\title{
Phragmalin Limonoids from Swietenia macrophylla and Their Antifeedant Assay against Mahogany Predator
}

\author{
Sônia G. S. R. Pamplona, ${ }^{a}$ Mara S. P. Arruda, ${ }^{a}$ Kelly C. F. Castro, ${ }^{b}$ \\ Consuelo Y. Y. e Silva, ${ }^{c}$ Antonio G. Ferreira, ${ }^{d}$ Maria F. G. F. da Silva, ${ }^{d}$ \\ Orlando S. Ohashi ${ }^{e}$ and Milton N. da Silva*,a \\ ${ }^{a}$ Laboratório de Cromatografia Líquida, Instituto de Ciências Exatas e Naturais, \\ Universidade Federal do Pará, 66075-110 Belém-PA, Brazil \\ ${ }^{b}$ Departamento de Biotecnologia, Universidade Federal do Oeste Paraense, \\ 68035-110 Santarém-PA, Brazil \\ 'Instituto de Ciências da Saúde, Faculdade de Farmácia, Universidade Federal do Pará, \\ 66074-110 Belém-PA, Brazil \\ ${ }^{d}$ Departamento de Química, Universidade Federal de São Carlos, \\ 13565-905 São Carlos-SP, Brazil \\ eDepartamento de Entomologia, Universidade Federal Rural da Amazônia, \\ 66077-830 Belém-PA, Brazil
}

\begin{abstract}
The purification of the hexanic extract from the leaves of a native variety of mahogany collected in Santarém (Pará, Brazil) afforded eight new phragmalin limonoids along with eight known compounds. This variety, according to field observations, should be considered resistant against the specialist insect Hypsipyla grandella, that attacks the terminal shoots only of juvenile mahogany and not of matured ones. After observing that four phragmalin limonoids were present just in mature leaves, we carried out two bioassays, one of them using a fraction from hexanic extract of mature leaves and another using a mix of four limonoids. The results of the bioassay using the isolated limonoids showed a direct effect on the larvae of $\mathrm{H}$. grandella, suggesting that these limonoids act as inhibitors of larvae growth. This should be the reason why larvae choose the young leaves for their development.
\end{abstract}

Keywords: limonoids, Swietenia macrophylla, antifeedant activity, mahogany

\section{Introduction}

Brazilian mahogany, known as big-leaf mahogany, has been extensively studied, indicating a wide variety of biological activities such as antimicrobial, ${ }^{1}$ antiinflammatory, ${ }^{2,3}$ antioxidant, ${ }^{4-6}$ hypolipidemic ${ }^{7-9}$ and antifeedant. $^{10,11}$

Despite all these biological activities, the high commercial value of sawn mahogany timber continues to deliver the greatest demand for this species. This factor stimulates uncontrolled exploitation with no concern for developing management techniques to preserve the species for future generations. ${ }^{12,13}$

*e-mail: yumilton@yahoo.com.br
Although efforts to establish large-scale homogeneous plantations of native Meliaceae species, these have almost invariably failed, due to larval attacks by the shoot borer Hypsipyla grandella (Lepidoptera: Pyralidae). The main damage from $H$. grandella is caused by the larvae, which destroys the terminal shoots of juvenile plants, producing low-branched economically useless trees. ${ }^{14,15}$

A great amount of emphasis has been placed on reforestation in Aurora do Pará, city of Pará (Brazil). In this area, seeds from several regions of the Amazon basin were planted at the Tramontina Farm, among them, native varieties from Santarém, Pará. Field observations, at Tramontina Farm, that Santarém varieties were less attacked by $H$. grandella larvae, led to the hypothesis that this was a case of resistance. To date, no selected mahogany 
materials aiming at resistance to $H$. grandella larvae are available. However, breeding for the selection of tolerant or resistant materials for further cloning and maintenance of characteristics has become an aspiration of the timber industry. ${ }^{16,17}$

There are only a few studies about intra-specific diversity effects, but fewer about these effects on plant antiherbivore defenses. Recently, Moreira et al..$^{18}$ conducted a large-scale field trials of Swietenia macrophylla King, manipulating their genotypic diversity and tree diversity species and measured the effects of such manipulation on the growth of mahogany and in damage from $\mathrm{H}$. grandella larvae. In addition, the authors measured its secondary metabolites (tannins and polyphenolic compounds) in stems and leaves. ${ }^{18,19}$

To determine the phytochemical basis of this possible resistance of indigenous varieties of $S$. macrophylla, we have now undertaken a further investigation of its leaves, whose extract provided eight new phragmalin limonoids (1-8) (Figure 1). Our previous investigations reported the presence of six phragmalin limonoids with an 8,9,30-ortho-ester unit (9-14)..$^{20}$ This data is in agreement with previous works showing the presence of phragmalin limonoids in species collected in Asia. ${ }^{21-24}$ According to Moghadamtousi et al., ${ }^{11}$ there seems not to be much variety in the class of compounds in S. macrophylla, since, among the 93 compounds listed in a phytochemical review, 77 of them belong to the limonoid class, among which 38 are phragmalin type.

Our taxonomic and ecologic interest in the Meliaceae, led our group to continue the investigation into big-leaf mahogany to find potential lead compounds with biological activity against $H$. grandella larvae, the main predator of these species. In addition, based on the preference of these larvae for young leaves from juvenile plants, we decided to compare the fingerprints of young and mature leaves from S. macrophylla, searching for differences that could explain this preference. Finally, we carried out two bioassays against $H$. grandella larvae, one using a limonoid-rich fraction and another using the limonoids 10, 11, 13 and 14 isolated from mature leaves in greater amounts. We focused on $\mathrm{H}$. grandella because it is the most important herbivore in terms of abundance and amount of damage inflicted on. ${ }^{25,26}$

\section{Experimental}

\section{General procedures}

Optical rotations were measured by using a PerkinElmer 241 polarimeter (Waltham, USA). Infrared (IR) spectra were recorded on a Bomem-FT/IR spectrometer (Québec, Canada). Nuclear magnetic resonance (NMR) spectra were recorded in $\mathrm{CDCl}_{3}$ at room temperature on a
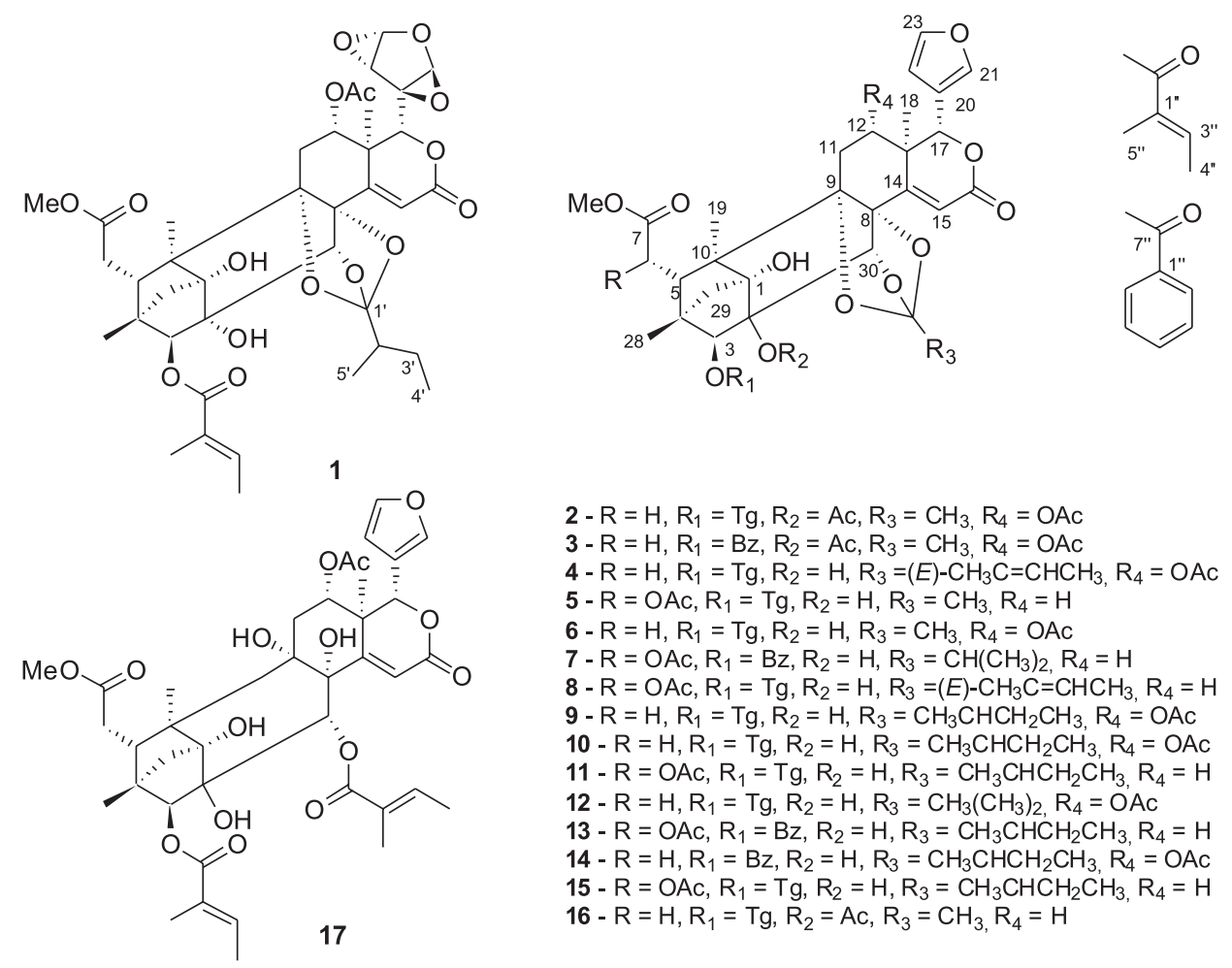

\footnotetext{
$2-\mathrm{R}=\mathrm{H}, \mathrm{R}_{1}=\mathrm{Tg}, \mathrm{R}_{2}=\mathrm{Ac}, \mathrm{R}_{3}=\mathrm{CH}_{3}, \mathrm{R}_{4}=\mathrm{OAc}$

$3-\mathrm{R}=\mathrm{H}, \mathrm{R}_{1}=\mathrm{Bz}, \mathrm{R}_{2}=\mathrm{Ac}, \mathrm{R}_{3}=\mathrm{CH}_{3}, \mathrm{R}_{4}=\mathrm{OAC}$

$4-\mathrm{R}=\mathrm{H}, \mathrm{R}_{1}=\mathrm{Tg}, \mathrm{R}_{2}=\mathrm{H}, \mathrm{R}_{3}=(E)-\mathrm{CH}_{3} \mathrm{C}=\mathrm{CHCH}_{3}, \mathrm{R}_{4}=\mathrm{OAC}$

$5-\mathrm{R}=\mathrm{OAc}, \mathrm{R}_{1}=\mathrm{Tg}, \mathrm{R}_{2}=\mathrm{H}, \mathrm{R}_{3}=\mathrm{CH}_{3}, \mathrm{R}_{4}=\mathrm{H}$

$6-\mathrm{R}=\mathrm{H}, \mathrm{R}_{1}=\mathrm{Tg}, \mathrm{R}_{2}=\mathrm{H}, \mathrm{R}_{3}=\mathrm{CH}_{3}, \mathrm{R}_{4}=\mathrm{OAC}$

$7-\mathrm{R}=\mathrm{OAc}, \mathrm{R}_{1}=\mathrm{Bz}, \mathrm{R}_{2}=\mathrm{H}, \mathrm{R}_{3}=\mathrm{CH}\left(\mathrm{CH}_{3}\right)_{2} \mathrm{R}_{4}=\mathrm{H}$

$8-\mathrm{R}=\mathrm{OAc}, \mathrm{R}_{1}=\mathrm{Tg}, \mathrm{R}_{2}=\mathrm{H}, \mathrm{R}_{3}=(E)-\mathrm{CH}_{3} \mathrm{C}=\mathrm{CHCH}_{3}, \mathrm{R}_{4}=\mathrm{H}$

$9-\mathrm{R}=\mathrm{H}, \mathrm{R}_{1}=\mathrm{Tg}, \mathrm{R}_{2}=\mathrm{H}, \mathrm{R}_{3}=\mathrm{CH}_{3} \mathrm{CHCH}_{2} \mathrm{CH}_{3}, \mathrm{R}_{4}=\mathrm{OAC}$

$10-\mathrm{R}=\mathrm{H}, \mathrm{R}_{1}=\mathrm{Tg}, \mathrm{R}_{2}=\mathrm{H}, \mathrm{R}_{3}=\mathrm{CH}_{3} \mathrm{CHCH}_{2} \mathrm{CH}_{3}, \mathrm{R}_{4}=\mathrm{OAC}$

$11-\mathrm{R}=\mathrm{OAc}, \mathrm{R}_{1}=\mathrm{Tg}, \mathrm{R}_{2}=\mathrm{H}, \mathrm{R}_{3}=\mathrm{CH}_{3} \mathrm{CHCH}_{2} \mathrm{CH}_{3}, \mathrm{R}_{4}=\mathrm{H}$

$12-\mathrm{R}=\mathrm{H}, \mathrm{R}_{1}=\mathrm{Tg}, \mathrm{R}_{2}=\mathrm{H}, \mathrm{R}_{3}=\mathrm{CH}_{3}\left(\mathrm{CH}_{3}\right)_{2}, \mathrm{R}_{4}=\mathrm{OAC}$

$13-\mathrm{R}=\mathrm{OAc}, \mathrm{R}_{1}=\mathrm{Bz}, \mathrm{R}_{2}=\mathrm{H}, \mathrm{R}_{3}=\mathrm{CH}_{3} \mathrm{CHCH}_{2} \mathrm{CH}_{3}, \mathrm{R}_{4}=\mathrm{H}$

$14-\mathrm{R}=\mathrm{H}, \mathrm{R}_{1}=\mathrm{Bz}, \mathrm{R}_{2}=\mathrm{H}, \mathrm{R}_{3}=\mathrm{CH}_{3} \mathrm{CHCH}_{2} \mathrm{CH}_{3}, \mathrm{R}_{4}=\mathrm{OAC}$

$15-\mathrm{R}=\mathrm{OAc}, \mathrm{R}_{1}=\mathrm{Tg}, \mathrm{R}_{2}=\mathrm{H}, \mathrm{R}_{3}=\mathrm{CH}_{3} \mathrm{CHCH}_{2} \mathrm{CH}_{3}, \mathrm{R}_{4}=\mathrm{H}$

$16-\mathrm{R}=\mathrm{H}, \mathrm{R}_{1}=\mathrm{Tg}, \mathrm{R}_{2}=\mathrm{Ac}, \mathrm{R}_{3}=\mathrm{CH}_{3}, \mathrm{R}_{4}=\mathrm{H}$
}

Figure 1. Chemical structures of limonoids isolated from the leaves of S. macrophylla. 
Bruker DRX 400 (Karlsruhe, Germany) and a Varian Mercury-300 NMR spectrometer (Palo Alto, CA, USA), and the solvent resonance was used as internal shift reference (tetramethylsilane as standard). The 2D NMR spectra were recorded by using standard pulse sequence.

Ultra-performance liquid chromatography-high resolution mass spectrometry (UPLC-HRMS) analysis was performed on a XEVO G2-S QTof mass spectrometer (Waters Corp., Milford, MA, USA) equipped with a lockspray source where an internal reference compound (leucine-enkephalin) was introduced simultaneously with the analyte for accurate mass measurements. Compounds were separated in a BEH C18 column (Waters Corp., Wexford, Ireland; $50 \mathrm{~mm} ; 2.1 \mathrm{~mm} ; 1.7 \mu \mathrm{m}$ particle size) using ultra-pure water (solvent $\mathrm{A}$ ) and methanol (solvent B). Column temperature was maintained at $37^{\circ} \mathrm{C}$.

Gradient elution was performed with ultra-pure water (solvent $\mathrm{A}$ ) and methanol (solvent $\mathrm{B}$ ), delivered at a flow rate of $0.45 \mathrm{~mL} \mathrm{~min}{ }^{-1}$ as follows: $50-80 \%$ of B in $20 \mathrm{~min}$. The gradient elution was followed by a 5 min post-run at initial conditions for equilibration of the column. The injection volume for the extract was $5 \mu \mathrm{L}$ at the concentration of $1 \mathrm{mg} \mathrm{mL}^{-1}$. The analysis was done in electrospray ionization (ESI) positive ion mode. For this, the same MS source parameters and UPLC conditions were applied.

Electrospray mass spectra data were recorded in a positive ionization mode for a mass range from $\mathrm{m} / \mathrm{z} 400$ to 1000 with a scan time of $0.1 \mathrm{~s}$. The source temperature was set to $150{ }^{\circ} \mathrm{C}$ with a cone gas flow of $20 \mathrm{~L} \mathrm{~h}^{-1}$. The desolvation gas flow was set to $600 \mathrm{~L} \mathrm{~h}^{-1}$ at a temperature of $250{ }^{\circ} \mathrm{C}$. The capillary was set at $3.5 \mathrm{kV}$ with cone voltage at $20 \mathrm{~V}$. MassLynx software (Waters, Milford, USA) was used for system control and data acquisition.

High-performance liquid chromatography (HPLC) preparative analyses was carried out in a preparative LC6A Shimadzu system with SPD-10AV UV detector (Tokyo, Japan). All solvents were filtered through a $0.45 \mathrm{~mm}$ membrane filter prior to use.

\section{Plant materials}

Swietenia macrophylla was collected at the Tramontina Farm, which is located about $220 \mathrm{~km}$ south of Belém $\left(2^{\circ} 10^{\prime} 50^{\prime \prime} \mathrm{S} ; 47^{\circ} 32^{\prime} 0.1^{\prime \prime} \mathrm{W}\right)$, Pará, Brazil, near the town of Aurora do Pará along the Belém-Paragominas Highway, in May 2010. The botanic material was identified by Prof Dr Orlando Shigueo Ohashi from the Botany Department, Universidade Federal Rural da Amazônia, Brazil. A voucher specimen (No. 1320a) was deposited at the Herbarium of the Botany Department, Universidade Federal Rural da Amazônia (Belém, Pará, Brazil).

\section{Extraction and isolation}

Ground leaves $(1.0 \mathrm{~kg})$ from S. macrophylla were extracted with hexane $(4 \mathrm{~L})$, at room temperature, two times. The concentrated hexane extract yielded $72 \mathrm{~g}$ of which $40 \mathrm{~g}$ were subjected to column chromatography (CC) over silica gel (70-230 mesh) under vacuum. Elution with hexane-EtOAc gradient yielded four fractions: Fr1 (hexane/EtOAc 90:10 v/v), Fr2 (hexane/EtOAc 70:30 v/v), Fr3 (hexane/EtOAc 50:50 v/v) and Fr4 (EtOAc). The ${ }^{1} \mathrm{H}$ NMR (300 MHz) spectra of these fractions showed that the major limonoids were in fraction $\mathrm{Fr} 3(1.53 \mathrm{~g})$ and Fr4 (1.82 g), the reunion of Fr3 and Fr4 fractions was named limonoid-rich fraction. A portion of this fraction was subjected to CC over silica gel (230-400 mesh). Elution with hexane-EtOAc gradient yielded ten fractions. Fractions $7(0.63 \mathrm{~g})$ and $8(0.82 \mathrm{~g})$ were applied, separately, on a Strata $\mathrm{C}_{18}$-E solid phase extraction (SPE) cartridge, $1000 \mathrm{mg}$ per $6 \mathrm{~mL}$ under vacuum. The SPE cartridge was previously conditioned with one volume $(6 \mathrm{~mL})$ of acetonitrile following by one volume of water. Then, an aliquot of $200 \mathrm{mg}$ of fractions 7 and 8 was solubilized in $4.8 \mathrm{~mL}$ of acetonitrile and sonicated for $1 \mathrm{~min}$, two times. After, $1.2 \mathrm{~mL}$ of water was added and sonicated for $1 \mathrm{~min}$ and applied on SPE cartridge. After elution, one additional volume of solution acetonitrile:water (8:2) was applied on SPE cartridge. The eluent was evaporated, and the residue was re-suspended in $4.0 \mathrm{~mL}$ of $\mathrm{MeOH}$ for each fraction, named 7a e 8a, respectively. Fractions 7a and 8a were purified by preparative HPLC, using a Phenomenex Gemini $\mathrm{C}_{18}$ column $(250 \times 10 \mathrm{~mm}$ i.d., Torrance, USA), an isocratic system of $\mathrm{H}_{2} \mathrm{O}-\mathrm{MeOH} 30: 70$ and a flow rate of $4.7 \mathrm{~mL} \mathrm{~min}{ }^{-1}$. To inject in HPLC system a loop of $500 \mu \mathrm{L}$ was used. UV detection was performed at $215 \mathrm{~nm}$. Fraction 7a yielded compounds $\mathbf{6}(15.7 \mathrm{mg}), \mathbf{3}(24.3 \mathrm{mg})$, 7 (13.9 mg), 2 (22.9 mg), 1 (10.6 mg), 5 (12.1 mg), $\mathbf{1 5}(10.7 \mathrm{mg}), \mathbf{9}(8.6 \mathrm{mg}), \mathbf{8}(8.8 \mathrm{mg})$ and $\mathbf{1 2}(9.4 \mathrm{mg})$, which showed chromatographic peaks with following retention times: $11.8 ; 12.5 ; 13.5 ; 14.1 ; 15.8 ; 21.9 ; 25.5 ; 27 ; 28.4$ and 28.5 min, respectively. Fraction 8 yielded compounds 4 (9.7 mg), $\mathbf{1 3}$ (28.3 mg), 10 (32.5 mg), 11 (32.7 mg) and $14(32.7 \mathrm{mg})$, which showed chromatographic peaks with following retention times: $32.2 ; 33.6 ; 36.8 ; 39.7$ and $46.3 \mathrm{~min}$.

\section{Growth inhibition assay}

Insects of $\mathrm{H}$. grandella used in this study were obtained from the culture maintained by the Entomology Laboratory of the Universidade Federal Rural da Amazônia (Belém, Pará, Brazil), and from natural field populations at the 
Tramontina Farm. Field collected larvae were removed from branches and were placed in previously sterilized glass tubes containing leaves of young shoots of Brazilian cedar (Cedrela odorata) and sealed with cotton. Feeding material was renewed every day. After pupation, the cocoons were sterilized with a 5\% sodium hypochlorite solution and then washed with water. The pupae were sexed (males have two lumps in the final segment and females only one fissure) and males and females were placed on filter paper in wooden cages $(50 \times 32.5 \times 32 \mathrm{~cm})$ covered externally by nylon screen. The average duration of the pupal stage was 10 days. Females oviposited about 100 eggs randomly distributed on filter paper. The filter paper on which oviposition took place was removed and replaced by new paper, if the female was still alive. The filter paper containing the eggs was cut and kept in a glass tube and a new rearing cycle was begun. Eggs hatch about three to four days after oviposition. Measurement of pupae and observations at the time of emergence were conducted under laboratory conditions at $28^{\circ} \mathrm{C}$. Bioassays were conducted at the Natural Products Laboratory of the Universidade Federal do Pará (Belém, Pará, Brazil).

For the first bioassay, the limonoid-rich fraction was dissolved in acetone at concentrations of 1.0, 2.0, 3.0, 5.0 and $10.0 \mathrm{mg} \mathrm{mL}^{-1}$. For the second bioassay, with limonoids $\mathbf{1 0}, 11,13$ and 14, isolated from the limonoid rich fraction, a stock solution, using acetone as solvent, was prepared, according to the ratio found in the leaves of this plant, that is, $1: 1: 2: 1$, respectively. From the stock solution, four work solutions were prepared in four concentration levels as follows: solution $1(0.25,0.25,0.5,0.25)$, solution 2 $(0.5,0.5,1.0,0.5)$, solution $3(0.75,0.75,1.5,0.75)$ and solution 4 (1.0, 1.0, 2.0, 1.0).

For both experiments, the diet for control group was prepared similarly, treated only with acetone. To determine larval development, fresh eggs of less than 24 hours old were used. After incubation, 126 larvae were used for the first bioassay and 60 for the second, all in the first instar, divided into 7 larvae per group for the first bioassay and 4 per group for the second. The larvae were kept inside glass flasks $(30 \mathrm{~mL})$, where they were fed with young leaves of Brazilian cedar $(2 \mathrm{~cm}$ in diameter) treated on a surface. An aliquot of $50 \mu \mathrm{L}$ of each treatment solution was pipetted on to leaf disks surface and the solvent was allowed to evaporate.

The larvae were weighed 10 and 5 days after the start of each bioassay, respectively. The average weight gain per larva was compared with control. The discs from treated leaves were replaced with fresh (treated) every day. The averages were compared by applying the Scheffé test $(p \leq 0.05)$.

\section{Results and Discussion}

The hexane extract from leaves of S. macrophylla was purified by classical chromatographic methods affording eight original phragmalin limonoids (1-8) (Figure 1), in addition to the known limonoids $3 \beta$ - $O$-detigloyl-3 $\beta$ - $O$-benzoyl$12 \alpha$-acetoxyswietephragmin D (9), $12 \alpha$-acetoxyswietephragmin C (10), 6-O-acetylswietephragmin E (11), $12 \alpha$-acetoxyswietephragmin D (12), 3 $\beta$ - $O$-detigloyl$3 \beta$ - $O$-benzoyl-6- $O$-acetylswietephragmin E (13), $3 \beta$ - $O$-detigloyl- $3 \beta$ - $O$-benzoy $1-12 \alpha$-acetoxyswietephragmin $\mathrm{C}(\mathbf{1 4})$ and 6-O-acetyl-3'-demethylswietephragmin E (15). The known limonoids, except for $\mathbf{1 5}$, have previously been isolated from the leaves of S. macrophylla specimens that were not described as native varieties. Limonoid $\mathbf{1 5}$ has been previously isolated from the fruits of S. macrophylla. ${ }^{2}$

Limonoid 1 exhibited similar NMR spectra (Tables S1 and S2, Supplementary Information (SI) section) to those of $12 \alpha$-acetoxyswietephragmin $\mathrm{C}(\mathbf{1 0}){ }^{20}$ The main differences observed in the ${ }^{1} \mathrm{H}$ NMR spectrum (Table S1, SI section) of compound $\mathbf{1}$ was the absence of the three downfield shifts signals attributable to a $\beta$-substituted furan ring. The heteronuclear multiple bond correlation (HMBC) spectrum of $\mathbf{1}$ showed correlation characteristics of a D-ring $\alpha, \beta$-unsaturated $\delta$-lactone limonoid. The signal at $\delta_{\mathrm{H}} 5.23$, assigned to $\mathrm{H}-17$, showed cross peaks with the ${ }^{13} \mathrm{C}$ NMR signals for C-13 $\left(\delta_{\mathrm{C}} 43.4\right), \mathrm{C}-14\left(\delta_{\mathrm{C}} 151.5\right), \mathrm{Me}-18\left(\delta_{\mathrm{C}} 15.7\right)$ and at $\delta_{\mathrm{C}} 61.0$ (quaternary), $51.0(\mathrm{CH})$ and $91.2(\mathrm{CH})$, allowing the assignment of these signals to C-20, C-22 and $\mathrm{C}-21$, since these were the only carbons left in the skeleton for a ${ }^{3} J$. However, these data could not be explained by the presence of a normal furan ring as in the limonoids described below. The ${ }^{13} \mathrm{C}$ signals at $\delta_{\mathrm{C}} 51.0$ showed onebond correlation with the ${ }^{1} \mathrm{H}$ signal at $\delta_{\mathrm{H}} 3.58(\mathrm{~d}, J=1.8 \mathrm{~Hz})$, which was coupled to the ${ }^{1} \mathrm{H}$ signal at $\delta_{\mathrm{H}} 5.51(\mathrm{dd}, J=1.8$, $\left.2.7 \mathrm{~Hz} ; \delta_{\mathrm{C}} 92.5\right)$. The latter was coupled to the ${ }^{1} \mathrm{H}$ signal at $\delta_{\mathrm{H}} 5.67\left(\mathrm{~d}, J=2.7 \mathrm{~Hz} ; \delta_{\mathrm{C}} 91.2\right)$. All HMBC correlations were compatible with a 20,21,22,23-diepoxyfuran ring. High-resolution electrospray ionization time-of-flight mass spectrometry (HR-ESI-ToF-MS) showed the molecular formula as $\mathrm{C}_{39} \mathrm{H}_{48} \mathrm{O}_{16}$ and confirmed structure 1 for this compound. In the g-NOESY (nuclear Overhauser effect spectroscopy) experiments, the observed NOE were similar to those found for compounds $\mathbf{2 - 8}$. The structure of the 20,21,22,23-diepoxyfuran ring received further support from the observed NOEs of the H-23 $\left(\delta_{\mathrm{H}} 5.51\right)$ on $\mathrm{H}-22\left(\delta_{\mathrm{H}} 3.58\right)$ and acetate group at $\mathrm{C}-12$ $\left(\mathrm{Me}, \delta_{\mathrm{H}} 2.21\right)$. The observed NOEs required the H-23 to be syn to H-22. Absence of NOEs between H-23 and $\mathrm{H}-21$ suggested that both hydrogens were in opposite 
faces of the furan ring ( $\mathrm{H}-23$ anti to $\mathrm{H}-21)$; thus, the relative stereochemistry of $\mathrm{H}-21$ and $\mathrm{H}-23$ is presumed to be $\beta$ and $\alpha$, respectively. The structure of the new natural product 1 was thus established as $12 \alpha$-acetoxyl$20 \beta, 21 \beta-22 \alpha, 23 \alpha$-diepoxyswietephragmin C. The structural assignment was also supported by comparison of the ${ }^{13} \mathrm{C}$ NMR spectrum (Table S2, SI section) with those of $12 \alpha$-acetoxyswietephragmin C (10). ${ }^{20}$

Limonoid 2 exhibited similar NMR spectra (Tables S1 and S2, SI section) to those of swietephragmin I (16; $\mathrm{C}_{36} \mathrm{H}_{42} \mathrm{O}_{13}$ ), which has previously been isolated from the leaves of $S$. macrophylla collected in Malaysia. ${ }^{27}$ HR-ESI-ToF-MS indicated the molecular formula to be $\mathrm{C}_{38} \mathrm{H}_{44} \mathrm{O}_{15}$ for compound 2 , requiring the presence of two additional oxygens and carbons in comparison with $\mathbf{1 6 .}$ The NMR spectra showed signals for the presence of two acetoxy groups $\left(\delta_{\mathrm{C}} 169.9,21.8,170.4,19.8 ; \delta_{\mathrm{H}} 2.20,1.52\right)$. Significant downfield shift for C-2 $\left(\delta_{\mathrm{C}} 83.8\right)$, when compared with 16, determined the position of an acetoxy at C-2. The methyl proton at $\delta_{\mathrm{H}} 1.56$ showed long-range correlations with the $\mathrm{C}-17$ signal $\left(\delta_{\mathrm{C}} 78.2\right)$ and the ${ }^{13} \mathrm{C}$ NMR signals at $\delta_{\mathrm{C}} 68.9(\mathrm{CH}$, by HETCOR (heteronuclear correlation) and DEPT $135^{\circ}$ (distortionless enhancement by polarization transfer)), 42.7 (quaternary), thus indicating a secondary hydroxyl or ester substituent at $\mathrm{C}-12$ and leading to their assignments as $\mathrm{H}_{3}-18, \mathrm{C}-12$ and $\mathrm{C}-13$, respectively. The C-12 signal at $\delta_{\mathrm{C}} 68.9$ showed one-bond correlation with the ${ }^{1} \mathrm{H}$ NMR signal at $\delta_{\mathrm{H}} 4.83(\mathrm{dd}, J=13.7$ and $4.0 \mathrm{~Hz})$ and a methyl signal at $\delta_{\mathrm{H}} 1.52$ showed a long-range correlation with the ${ }^{13} \mathrm{C}$ NMR signals at $\delta_{\mathrm{C}} 170.4$, indicating an acetoxyl group at C-12. In the $\mathrm{g}$-NOESY experiments, the observed NOE were similar to those found for compound $\mathbf{1}$. In addition, g-NOESY experiments showed NOE between $\mathrm{H}-12\left(\delta_{\mathrm{H}} 4.83\right)$ and $\mathrm{H}-17\left(\delta_{\mathrm{H}} 5.87\right), \mathrm{H}-5\left(\delta_{\mathrm{H}} 2.34\right)$ and $\mathrm{H} \beta-6\left(\delta_{\mathrm{H}} 2.31\right)$, indicating a $\beta$-orientation for these four hydrogens. Thus, the structure of the new limonoid was characterized as $12 \alpha$-acetoxyswietephragmin I (2). The structural assignment was also supported by comparison of the ${ }^{13} \mathrm{C}$ NMR spectrum (Table S2, SI section) with that of swietephragmin I (16), and 3 $\beta$ - $O$-detigloyl-3 $\beta$-O-benzoyl$12 \alpha$-acetoxyswietephragmin D (9).

The geometry of the C-2"/C-3" double bond was determined from the chemical shift of H-3" $\left(\delta_{\mathrm{H}} 6.65 \mathrm{dq}\right.$, $J=6.9,1.4 \mathrm{~Hz}, E$-isomer) and its comparison with that of methyl angelate $\left(\delta_{\mathrm{H}} 5.97, Z\right.$-isomer) and methyl tiglate $\left(\delta_{\mathrm{H}} 6.72, E\right.$-isomer $){ }^{28}$ The two methyl ${ }^{1} \mathrm{H}$ signals are easily distinguished on the basis of the vicinal $\mathrm{H}-\mathrm{H}$ coupling constants, since a large vicinal coupling (ca. $7 \mathrm{~Hz}$ ) is only expected for the Me-4" protons. ${ }^{29}$ In methyl angelate the methyl group geminal to the carboxy function appears at $\delta_{\mathrm{C}} 20.2$ and that geminal to the vinyl proton at $\delta_{\mathrm{C}} 15.9$, while tiglate shows resonances at $\delta_{\mathrm{C}} 10.9$ and 13.8, respectively, as opposed to the low-field shift for Me at C-3. Thus, assignment of Me-4" ( $\delta_{\mathrm{H}} 1.69 \mathrm{dd}, J=6.9$, $1.2 \mathrm{~Hz}$ ) was made by means of a coupling constant with H-3". The methyl hydrogen at $\delta_{\mathrm{H}} 1.69$ showed a onebond correlation (HETCOR) with the ${ }^{13} \mathrm{C}$ NMR signal at $\delta_{\mathrm{C}}$ 13.6, which was more deshielded than that for Me-5" $\left(\delta_{\mathrm{C}} 13.0\right)$. The same rationale applies to the chemical shifts of the hydrogens of tigloyl ester substituent in compounds 10-12 and 15. The heteronuclear single quantum correlation (HSQC) and HETCOR experiments on compounds 10-12 and $\mathbf{1 5}$ permitted minor corrections to previous ${ }^{13} \mathrm{C} \mathrm{NMR}$ assignments, ${ }^{20}$ the signals for Me-4" and Me-5" were reassigned (11, Me-4": 14.3, Me-5": 12.4; 12, Me-4": 14.5, Me-5": 12.4; 10 and 15, see Table S2, SI section).

Limonoid 3 showed spectral characteristics close to those of 2. The principal differences observed in the ${ }^{1} \mathrm{H}$ and ${ }^{13} \mathrm{C}$ NMR spectra (Tables S1 and S2, SI section) of $\mathbf{3}$ when compared to limonoid $\mathbf{2}$ was the replacement of resonances for a tigloyl ester by signals for a benzoate group $\left(\delta_{\mathrm{H}} 7.97 \mathrm{dd}, J=8.3\right.$ and $1.3 \mathrm{~Hz}, 2 \mathrm{H} ; 7.43 \mathrm{~m}, 2 \mathrm{H}$; $\left.7.58 \mathrm{~m} ; \delta_{\mathrm{C}} 166.5,131.2,128.9,2 \mathrm{C}, 128.7,2 \mathrm{C}, 133.2\right)$. The HMBC experiment, in addition to showing correlations similar to those for 2 , revealed a cross peak of the ${ }^{1} \mathrm{H}$ NMR signal at $\delta_{\mathrm{H}} 5.49$, assigned to $\mathrm{H}-3$, with the ${ }^{13} \mathrm{C} \mathrm{NMR}$ signal at $\delta_{\mathrm{C}} 166.5$, helping to determine the position of the benzoate group at $\mathrm{C}-3$. This conclusion was supported by the correlation observed between the aromatic ${ }^{1} \mathrm{H}$ NMR signal at $\delta_{\mathrm{H}} 7.97$ and the ${ }^{13} \mathrm{C}$ NMR signal at $\delta_{\mathrm{C}} 166.5$. HR-ESI-ToF-MS showed the molecular formula as $\mathrm{C}_{40} \mathrm{H}_{42} \mathrm{O}_{15}$ and confirmed structure 3 for this compound. In the g-NOESY experiment, the observed NOE were similar to those found for 2 . The structure of the new natural product 3 was thus established as $3 \beta$ - $O$-detigloyl3 $\beta$-O-benzoyl-12 $\alpha$-acetoxyswietephragmin I.

Limonoid 4 exhibited similar NMR spectra (Tables S1 and S2, SI section) to those of $12 \alpha$-acetoxyswietephragmin C (10). The principal differences observed in the NMR spectra (Tables S1 and S2, SI section) of compound $\mathbf{4}$ was the presence of additional signals of an olefinic hydrogen $\left(\delta_{\mathrm{H}} 6.14 \mathrm{dq}, J=7.0,1.4 \mathrm{~Hz}\right)$ and two vinylic methyl groups $\left(\delta_{\mathrm{H}} 1.71 \mathrm{brs}, 3 \mathrm{H}, \delta_{\mathrm{C}} 11.7 ; 1.68, \mathrm{~d}, 3 \mathrm{H}, J=7.0 \mathrm{~Hz}, \delta_{\mathrm{C}} 13.4\right)$, typical of the tigloyl group. An oxymethine proton at $\delta_{\mathrm{H}} 4.54$ showed one-bond correlation with the ${ }^{13} \mathrm{C} \mathrm{NMR}$ signals at $\delta_{\mathrm{C}} 78.1$ (HETCOR). The ${ }^{13} \mathrm{C}$ NMR signals at $\delta_{\mathrm{C}} 124.5,83.6$ and 86.5, all quaternary, in comparison with compounds 1-15 suggested the presence of an ortho-2-methylbutenoate group at C-8, C-9, and C-30, and permitted the assignment of the signals at $\delta_{\mathrm{H}} 4.54$ to $\mathrm{H}-30$, $\delta_{\mathrm{C}} 78.1$ to $\mathrm{C}-30, \delta_{\mathrm{C}} 124.5$ to orthoester carbon, $\delta_{\mathrm{C}} 83.6$ and 86.4 to C-8 and C-9, respectively. Swietemacrophine (17), 
isolated from the leaves of $S$. macrophylla collected in Malaysia, ${ }^{27}$ represents an intermediate in the formation of 8,9,30-ortho-tigloylate and converts in compound $\mathbf{4}$. In the g-NOESY experiment, the observed NOE were similar to those found for $\mathbf{1 0} .^{38}$ Thus, the structure of the new natural product 4 was established as 8,9,30-orthotigloylate-swietemacrophine. HR-ESI-ToF-MS showed the molecular formula as $\mathrm{C}_{39} \mathrm{H}_{46} \mathrm{O}_{14}$ and confirmed structure $\mathbf{4}$ for this compound.

Limonoid 5 exhibited similar NMR spectra (Tables S1 and $\mathrm{S} 2$, SI section) to those of limonoid $2\left(\mathrm{C}_{38} \mathrm{H}_{44} \mathrm{O}_{15}\right)$. The molecular formula was established by HR-ESI-ToF-MS $\left(\mathrm{C}_{36} \mathrm{H}_{42} \mathrm{O}_{14}\right)$, indicating the absence of one oxygen and two carbons in comparison with 2 . The NMR spectra showed signals for only one acetoxyl group at $\delta_{\mathrm{H}} 2.23$ $\left(\delta_{\mathrm{C}} 21.0\right.$ and 169.8$)$. The C-6 signal at $\delta_{\mathrm{C}} 71.4$ showed a ${ }^{1} J$ correlation with the ${ }^{1} \mathrm{H}$ NMR signal at $\delta_{\mathrm{H}} 5.48$ (s), which showed a long-range correlation with the ${ }^{13} \mathrm{C}$ NMR signal at $\delta_{\mathrm{C}} 169.8$, indicating an acetoxyl group at C-6 position (Figure 2). In addition, the upfield shift observed for C-2 $\left(\delta_{\mathrm{C}} 75.6\right)$, when compared with compounds $\mathbf{1}$ and $\mathbf{4}$, was coherent with a hydroxyl group at this position. Thus, the structure was proposed as 2-deacetyl-6-acetoxylswietephragmin I (5).

Limonoid $\mathbf{6}$ showed spectroscopic characteristics close to those of 5. HR-ESI-ToF-MS indicated the molecular formula to be $\mathrm{C}_{36} \mathrm{H}_{42} \mathrm{O}_{14}$, which suggests that this compound is an isomer of $\mathbf{5}$. The methyl proton at $\delta_{\mathrm{H}} 1.51$ showed long-range correlation with the $\mathrm{C}-17$ signal $\left(\delta_{\mathrm{C}} 78.2\right)$ and $\delta_{\mathrm{C}} 68.6\left(\mathrm{CH}\right.$ by HETCOR and DEPT $\left.135^{\circ}\right), 42.7$ (quaternary), thus indicating the secondary acetoxyl group in compound 6 to be located at C-12 and leading to their assignments as $\mathrm{H}_{3}-18, \mathrm{C}-12$ and $\mathrm{C}-13$, respectively. Thus, the structure of a new natural product was established as 2-deacetyl-12 $\alpha$-acetoxyswietephragmin I (6).
Limonoid 7 showed spectroscopic characteristics close to those of $3 \beta$-O-detigloyl-3 $\beta$-O-benzoyl$12 \alpha$-acetoxyswietephragmin D (9). HR-ESI-ToF-MS indicated the molecular formula to be $\mathrm{C}_{40} \mathrm{H}_{44} \mathrm{O}_{14}$, which strongly suggests that this compound is an isomer of 9. However, the oxymethyne proton at $\delta_{\mathrm{H}} 5.54$ showed a one-bonded correlation with the ${ }^{13} \mathrm{C}$ NMR signal at $\delta_{\mathrm{C}} 71.4$ and long-range correlation with the signal for C-5 and the ${ }^{13} \mathrm{C}$ NMR signal at $\delta_{\mathrm{C}} 169.8$ and 171.3. The methoxyl singlet at $\delta_{\mathrm{H}} 2.25$ correlated to $\delta_{\mathrm{C}} 169.8$, indicating the presence of a carbomethoxy group at C-7 and acetoxyl substituent at C-6. This data indicated a secondary acetoxyl substituent now affixed to $\mathrm{C}-6$. The structure of the new natural product was thus established as $3 \beta-O$-detigloyl-3 $\beta$ - $O$-benzoyl6- $O$-acetylswietephragmin $\mathrm{D}$. The structural assignment was also supported by comparison of the ${ }^{13} \mathrm{C}$ NMR spectrum (Table S2, SI section) with those of 6- $O$-acetyl3'-demethylswietephragmin E (15) and 3 $\beta$ - $O$-detigloyl$3 \beta$ - $O$-benzoyl-12 $\alpha$-acetoxyswietephragmin D (9).

The HR-ESI-ToF-MS and NMR spectra (Tables S1 and S2, SI section) confirmed an isomer of $\mathbf{4}$ for limonoid $\mathbf{8}$ $\left(\mathrm{C}_{39} \mathrm{H}_{46} \mathrm{O}_{14}\right)$. One of the differences observed in the ${ }^{1} \mathrm{H}$ and ${ }^{13} \mathrm{C}$ NMR spectra was the replacement of the resonances for an acetoxyl substituent at C-12 signals for this group at C-6. This was supported by the absence of double duplet signal observed due to an acetoxyl group attached in C-12, as well as the presence of the ${ }^{13} \mathrm{C}$ NMR signal at $\delta_{\mathrm{C}} 71.4$, as observed for limonoid 7 . The structure was established as 6-acetoxyl-12 $\alpha$-deacetoxyl-8,9,30-ortho-tigloylateswietemacrophine (8), a new natural product.

Based on the hypothesis that the Santarém variety might have a resistance to the larvae of $H$. grandella, we investigated its chemical composition, using LC-HR-ESI-ToF-MS through fingerprint analysis, focusing specially on
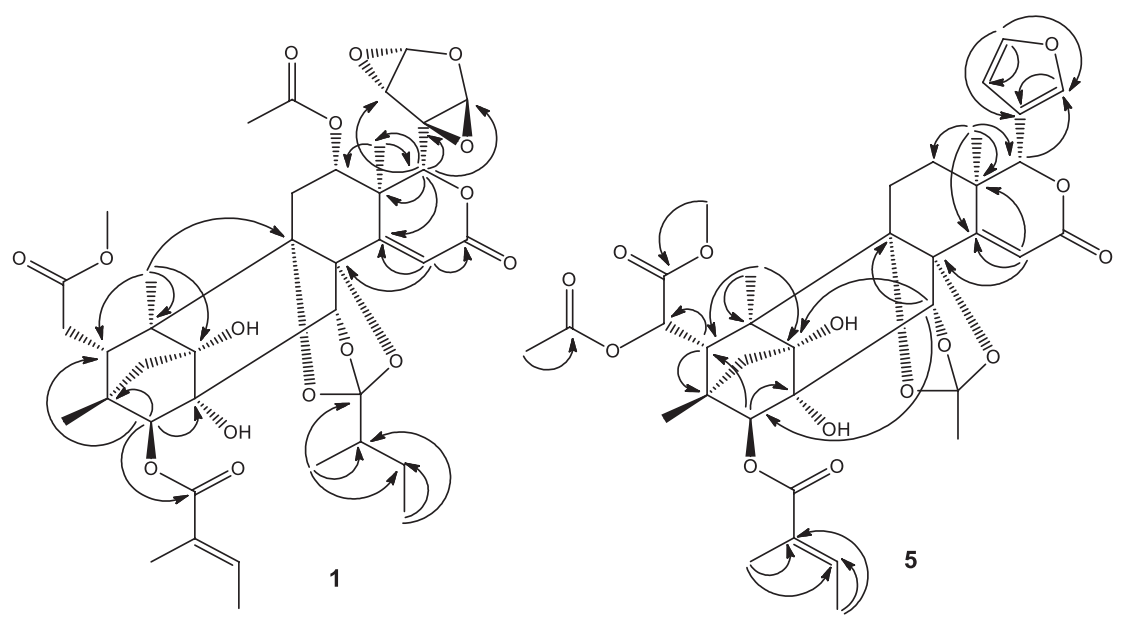

Figure 2. Selected HMBC correlations of $\mathbf{1}$ and $\mathbf{5}$. 


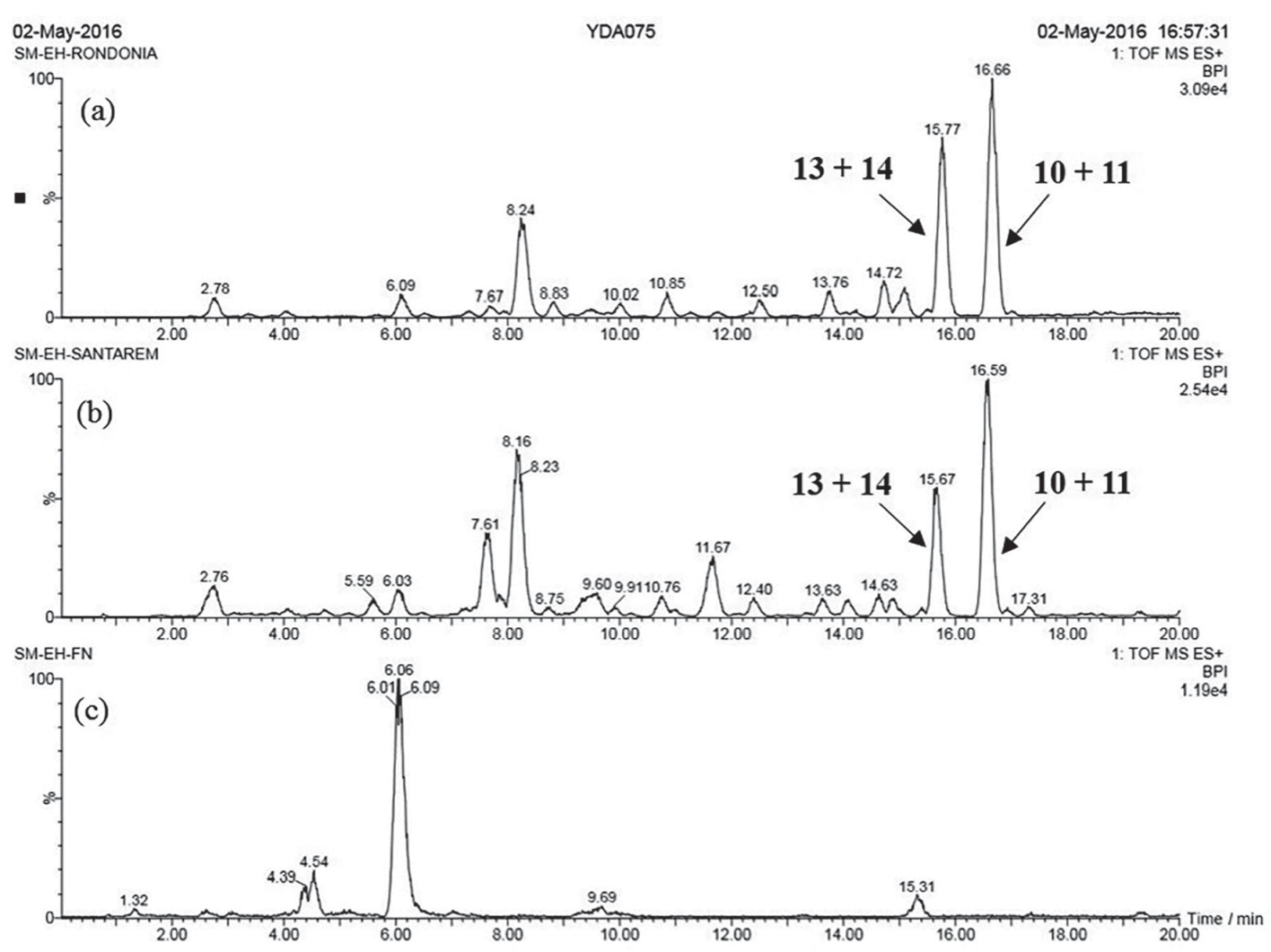

Figure 3. Representative total ion current chromatograms of hexanic extracts of Swietenia macrophylla King of: (a) matured leaves from Rondônia variety (susceptible); (b) matured leaves from Santarém variety (resistant) and (c) young leaves.

limonoids content, since they are the taxonomic markers of Meliaceae. In this study, we compared the resistant variety with a susceptible one (Figure 3).

Moreira et al. ${ }^{18}$ found that both forms of plant diversity had positive effects on the stem (but not leaf) defenses. However, it is known that the larvae of $\mathrm{H}$. grandella, after hatching, feed exclusively on young leaves and only after some time they do penetrate inside apical buds. In this sense, our studies suggest that there should be a "perception" by the larvae of the presence of the main taxonomic markers for the Meliaceae, the limonoids.

Based on the hypothesis that the preference of $H$. grandella larvae by young leaves can be due to different limonoids or concentrations thereof, we have analyzed young and matured leaf extracts using LC-MS. As observed in Figure 3, the limonoids 10, 11, 13 and $\mathbf{1 4}$ are absent in the young leaves, but occur in matured leaves. This difference in chemical composition between the young and matured leaves motivated our group to test these limonoids against the $H$. grandella larvae.

Due to the necessity of reasonable quantities of pure compounds for the development of bioassay with the larvae of $H$. grandella, since the substances would be administered by dispensing a solution on the surface of Brazilian cedar leaves $(2 \mathrm{~cm}$ discs $)$, the first experiment was carried out with limonoid-rich fraction. The experiment with a rich fraction from S. macrophylla mature leaves containing limonoids 10, 11, 13 and 14, showed significant reduction in the larval weight of H. grandella in 10 days, as showed in Figure 4.

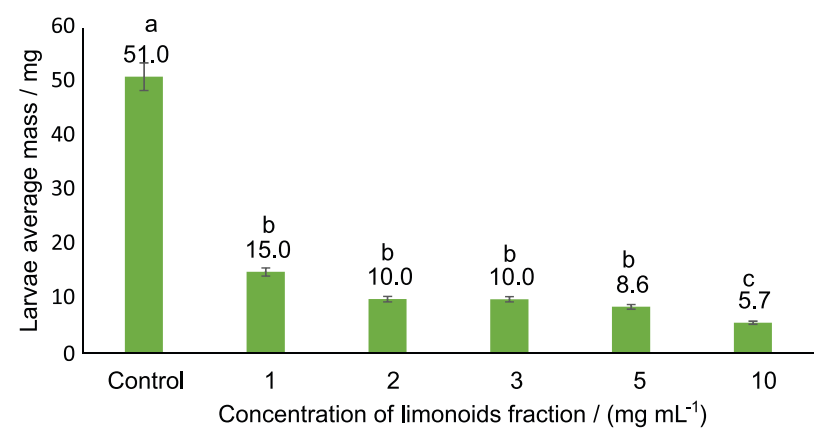

Figure 4. Effect of limonoid-rich fraction on growth of $H$. grandella larvae. Means followed by the same letters indicate no significant difference $(p \leq 0.05)$ in the Scheffé test.

The average weights of the surviving larvae were 15.0, $10.0,10.0,8.6$ and $5.7 \mathrm{mg}$ corresponding to $70,80,80,83$ and $89 \%$ of weight reduction percentage at 1.0, 2.0, 3.0, 5.0 and $10.0 \mathrm{mg} \mathrm{mL}^{-1}$ of fraction, respectively (Scheffé test, $p \leq 0.05$ ), when compared with the average weight of control group $(51.0 \mathrm{mg})$. 
Based on the results obtained with the fraction, the next experiment was carried out with a mixed solution containing the limonoids $\mathbf{1 0}, \mathbf{1 1}, \mathbf{1 3}$ and $\mathbf{1 4}$. The bioassay was conducted over a period of 5 days, at four concentration levels: $0.25,0.50,0.75$ and $1.00 \mathrm{mg} \mathrm{mL}^{-1}$ for limonoids $\mathbf{1 0}$, $\mathbf{1 1}$ and $\mathbf{1 4}$ and at $0.50,1.00,1.50$ and $2.00 \mathrm{mg} \mathrm{mL}^{-1}$ for $\mathbf{1 3}$, according to the available masses of the isolated limonoids, given that a great amount of these substances would be necessary to carry on the bioassays. Figure 5 shows the effect of limonoids 10, 11, 13 and $\mathbf{1 4}$ on $\mathrm{H}$. grandella larvae in which a reduction of larval weight between $21-53 \%$ compared with control could be observed.

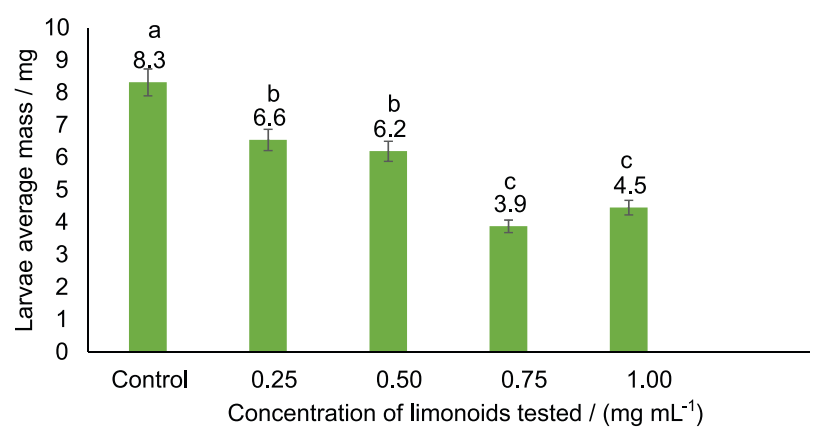

Figure 5. Effect of mixture of limonoids 10, 11, 13 (at 0.25, 0.50, 0.75 and $1.00 \mathrm{mg} \mathrm{mL}^{-1}$ ) and $\mathbf{1 4}$ (at $0.50,1.00,1.50$ and $2.00 \mathrm{mg} \mathrm{mL}^{-1}$ ), on growth of $H$. grandella larvae. Means followed by the same letters indicate no significant difference $(p \leq 0.05)$ in the Scheffé test.

\section{Conclusions}

Based on these findings, we observed no qualitative differences between resistant and susceptible leaf fingerprints on known limonoid contents, but we should not ignore that there seems to be a different proportion between the isomers of mass 795.2840 ( $\mathbf{5}$ and an unknown limonoid) and the isomers of mass 763.2602 (13 and 14). Nevertheless, it is premature to draw any conclusions about the role of all limonoids present on the mahogany leaves against the $H$. grandella larvae, until they can be evaluated directly in bioassays with this insect. It is interesting to emphasize that the effects obtained in this experiment with limonoids 10, 11, 13 and $\mathbf{1 4}$ showed a direct effect on the larvae of $H$. grandella, suggesting that these limonoids could act as inhibitors of growth. This effect may be the probable reason for the larvae choosing young leaves, since the limonoids 10, 11, 13 and 14 occur in large amounts in matured leaves, but are not present in young leaves.

\section{Supplementary Information}

Supplementary data $\left({ }^{1} \mathrm{H},{ }^{13} \mathrm{C}, \mathrm{HSQC}\right.$ and HMBC NMR spectra of compounds 1-8) are available free of charge at http://jbcs.sbq.org.br as PDF file.

\section{Acknowledgments}

The authors are grateful to Conselho Nacional de Desenvolvimento Científico e Tecnológico (CNPq), Fundação de Amparo à Pesquisa do Estado de São Paulo (FAPESP), Fundação de Amparo à Pesquisa do Estado do Pará (FAPESPA) and Coordenação de Aperfeiçoamento de Pessoal de Ensino Superior (CAPES) for their financial support. We are also thankful to Dr Norberto P. Lopes from the Faculdade de Ciências Farmacêuticas de Ribeirão Preto, USP, for the HRESITOF-MS.

\section{References}

1. Maiti, A.; Dewanjee, S.; Mandal, S. C.; Annadurai, S.; Iran. J. Pharmacol. Ther. 2007, 6, 99.

2. Chen, J.-J.; Huang, S.-S.; Liao, C.-H.; Wei, D.-C.; Sung, P.-J.; Wang, T.-C.; Cheng, M.-J.; Food Chem. 2010, 120, 379.

3. Guevara, A.; Apilado, A.; Sakurai, H.; Kozuka, M.; Takuda, H.; Philipp. J. Sci. 1996, 125, 271.

4. Falah, S.; Suzuki, T.; Katayama, T.; Pak. J. Biol. Sci. 2008, 11, 2007.

5. Kalpana, K.; Pugalendi, K.; J. Basic Clin. Physiol. Pharmacol. 2011, 22, 11.

6. Pamplona, S.; Sá, P.; Lopes, D.; Costa, E.; Yamada, E.; Silva, C.; da Silva, M.; Molecules 2015, 20, 18777.

7. Maiti, A.; Dewanjee, S.; Jana, G.; Mandal, S.; Int. J. Green Pharm. 2008, 2, 224.

8. Maiti, A.; Dewanjee, S.; Kundu, M.; Mandal, S.; Pharm. Biol. 2009, 47, 132.

9. Dewanjee, S.; Maiti, A.; Das, A.; Mandal, S.; Dey, S.; Fitoterapia 2009, 80, 249.

10. Mootoo, B.; Ali, A.; Motilal, R.; Pingal, R.; Ramlal, A.; Khan, A.; J. Nat. Prod. 1999, 62, 1514.

11. Moghadamtousi, S. Z.; Goh, B. H.; Chan, C. K.; Shabab, T.; Kadir, H.; Molecules 2013, 18, 10465.

12. Grogan, J.; Blundell, A.; Landis, R.; Youatt, A.; Gullison, R.; Martinez, M.; Conserv. Lett. 2010, 3, 12.

13. Brown, N.; Jennings, S.; Clements, T.; Perspect. Plant Ecol. Evol. Syst. 2003, 6, 37.

14. Júnior, M. L. S.; Júnior, J.; Braga, A. C. M.; Ohashi, O. S.; Melo, V. S.; Silva, G. R.; Pedroso, A. J. S.; Viégas, I. J. M.; Saldanha, E. C. M.; Rev. Árvore 2014, 38, 1085.

15. da Silva, M. F. G. F.; Agostinho, S. M. M.; Paula, J. R.; Neto, J. O.; Castro-Gamboa, I.; Filho, E. R.; Pure Appl. Chem. 1999, $71,1083$.

16. https://www.alice.cnptia.embrapa.br/alice/handle/doc/668553, accessed in July 2017. 
17. Lemes, M. R.; Gribel, R.; Proctor, J.; Grattapaglia, D.; Mol. Ecol. 2003, 12, 2875.

18. Moreira, X.; Abdala-Roberts, L.; Parra-Tabla, V.; Mooney, K. A.; PLoS One 2014, 9, e105438.

19. Abarquez, A.; Bush, D.; Ata, J.; Tolentino Jr., E. L.; Gilbero, D.; J. Trop. For. Sci. 2015, 27, 314.

20. da Silva, M. N.; Arruda, M. S. P.; Castro, K. C. F.; da Silva, M. F. G. F.; Fernandes, J. B.; Vieira, P. C.; J. Nat. Prod. 2008, 71, 1983.

21. Lin, B. D.; Zhang, C. R.; Yang, S. P.; Zhang, S.; Wu, Y.; Yue, J. M.; J. Nat. Prod. 2009, 72, 1305.

22. Lin, B. D.; Zhang, C. R.; Yang, S. P.; Wu, Y.; Yue, J. M.; Chem. Pharm. Bull. 2011, 59, 458.

23. Liu, J. Q.; Wang, C. F.; Chen, J. C.; Qiu, M. H.; Nat. Prod. Res. 2012, 26, 1887.
24. Tian, L.; Teng, X.; Zhong, C.; Xie, Y.; Gen. Chem. 2015, 1, 22.

25. Maia, B. H. L. N. S.; Paula, J. R.; Sant'Ana, J.; Silva, M. F. G. F.; Fernandes, J. B.; Vieira, P. C.; Costa, M. S. S.; Ohashi, O. S.; Silva, J. N. M.; J. Braz. Chem. Soc. 2000, 11, 629.

26. Lunz, A. M.; Tomazini, M. J.; Moraes, M. C. B.; Neves, E. J. M.; Batista, T. F. C.; Degenhardt, J.; de Sousa, L. A.; Ohashi, O. S.; Pesq. Flor. Bras. 2009, 59, 45.

27. Tan, S. K.; Osman, H.; Wong, K. C.; Boey, P. L.; Food Chem. 2009, 115, 1279.

28. Jackman, L. M.; Wiley, R. H.; J. Chem. Soc. 1960, 2881.

29. Joseph-Nathan, P.; Wesener, J. R.; Günther, H.; Magn. Reson. Chem. 1984, 22, 190.

Submitted: September 5, 2017 Published online: February 26, 2018 